\title{
Prevalence, frequency, and duration of hypnotic drug use among the elderly living at home
}

\author{
KEVIN MORGAN, HELEN DALLOSSO, SHAH EBRAHIM， TOM ARIE， PETER H FENTEM
}

\begin{abstract}
Details of consumption of hypnotic drugs derived from a nationally representative sample of elderly people were analysed in terms of the prevalence, duration, and likely frequency of use. Of 1020 randomly selected subjects aged 65 and over $16 \%$ (166) reported using (mainly benzodiazepine) hypnotic drugs, and of these $89 \%$ reported having taken such a drug the night before the interview. Most of these users (73\%) had been taking hypnotic drugs for more than one year, with $25 \%$ reporting drug use for more than 10 years.

These results suggest that for most elderly users of hypnotic drugs, patterns of consumption encourage the development of cumulative effects and benzodiazepine dependence.

\section{Introduction}

Most of the disadvantages associated with the use of hypnotic drugs in the elderly are directly related to the continuity and duration of drug use. Thus confusional states, ${ }^{1}$ impaired psychomotor performance, ${ }^{2}$ increased daytime anxiety, ${ }^{3}$ rebound insomnia, ${ }^{4}$ and dependence $\mathrm{s}^{\mathrm{s}}$ are all more likely if the hypnotic drug is taken regularly over long periods. The type of hypnotic drug taken also influences unwanted side effects, with long acting drugs being more likely to accumulate and disrupt daytime activities, ${ }^{2}$ while very short acting drugs produce an earlier and more severe rebound on withdrawal. ${ }^{6}$ Surveys of hypnotic drug use, however, have tended to focus mainly on overall use, paying less (if any) attention to the
\end{abstract}

\footnotetext{
The Activity and Ageing Research Group, Departments of Health Care of the Elderly and of Physiology and Pharmacology, University of Nottingham Medical School, Queen's Medical Centre, Nottingham NG7 2UH

KEVIN MORGAN, BSC, PHD, lecturer

HELEN DALLOSSO, MSC, PHD, research fellow

SHAH EBRAHIM, DM, MRCP, lecturer

TOM ARIE, FRCP, FRCPSYCH, professor, department of health care of the elderly

PETER H FENTEM, MSC, MRCP, professor, department of physiology and pharmacology

Correspondence to: Dr Kevin Morgan.
}

particular drugs prescribed or the frequency and duration with which such drugs are taken. If surveys of the use of hypnotic drugs among the elderly are to serve as useful feedback this additional information is essential. Here we describe the characteristics and implications of hypnotic drug use in a large random sample of elderly people living at home.

\section{Patients and methods}

Data were derived from the activity and aging survey, full details of which are presented elsewhere. ${ }^{78}$ Briefly, the study was designed to investigate relations between mental and physical health, psychological wellbeing, and customary physical activity among the old (aged 65-74) and the very old (aged 75 or over) living at home. Quality of sleep was identified as an important index of both physical and psychological wellbeing. Of 1599 elderly patients randomly selected from the Nottinghamshire Family Practitioner Committee's records (747 aged $65-74 ; 852$ aged 75 or over) an effective sample of 1299 were available for interview. Causes of loss from the original target sample included death, admission to hospital or residential care, and change of address. Of the sample of 1299, 1042 agreed to participate in the survey (a reponse rate of $80 \%$ ). Within this stratified sample the age group $\geqslant 75$ was intentionally overrepresented to admit sufficient numbers for both present and prospective analyses. Thus while the ratio of "old" to "very old" people in the general population is roughly $1 \cdot 62: 1,{ }^{9}$ a ratio of $1: 1$ was aimed at in this survey.

Interviews were conducted between May and September 1985 by 10 women aged 27-56. Each interviewer received two weeks of intensive classroom based training and was closely monitored for a further two weeks of practical experience. The structured questionnaire covered aspects of health and lifestyle and included questions about subjective characteristics of sleep, the existence and nature of sleep problems, and currently prescribed hypnotic drugs. Reported use of drugs was verified by the interviewer, who was instructed to ask for and examine tangible evidence of prescribed medication (bottles, cartons, prescriptions, etc). Hypnotics were defined as prescription drugs with sedative properties, the administration of which was intended to promote sleep.

Results

PREVALENCE AND FREQUENCY OF USE

Information on use of hypnotic drugs was available from 1020 respondents. The distribution of responses to the question "Do you ever 
take tablets to help you get to sleep?" is shown in table I. A total of 166 respondents (16\%) reported using prescription hypnotics at least "sometimes," equivalent to a weighted prevalence (correcting for the over sampled $\geqslant 75$ age group) of $15 \%$. Levels of use of hypnotic drugs increased significantly with age, showing a prevalence of $13 \%$ among those aged $65-74$, and $20 \%$ among those aged $\geqslant 75\left(\chi^{2}=9 \cdot 02, \mathrm{df}=1, \mathrm{p}<0.005\right)$. When the results for the sexes were analysed separately, however, this age related increase was significant only for women, who, overall, were more likely to report using drugs to help them sleep than were men (table II).

TABLE I-Distribution of responses to the question "Do you ever take tablets to help you get to sleep?"

\begin{tabular}{lc}
\hline \multicolumn{1}{c}{ Response } & No (\%) \\
\hline Never/seldom & patients answering \\
Sometimes & $854(84)$ \\
Often & $27(3)$ \\
All the time & $14(1)$ \\
\hline Total (unweighted) & $125(12)$ \\
\hline
\end{tabular}

TABLE II-Reported hypnotic drug use by sex

\begin{tabular}{lcc}
\hline & No (\%) of men & No (\%) of women \\
\hline Hypnotics used at least sometimes & $39(10)$ & $127(20)$ \\
Hypnotics used seldom or never & $359(90)$ & $495(80)$ \\
\hline Total & 398 & 622 \\
\hline
\end{tabular}

$\chi^{2}=19 \cdot 31, \mathrm{df}=1, \mathrm{p}<0 \cdot 001$.

TABLE III-Distribution of hypnotic drugs prescribed

\begin{tabular}{lc|lc}
\hline $\begin{array}{c}\text { Generic name or } \\
\text { drug group }\end{array}$ & $\begin{array}{c}\text { No(\%) of patients } \\
\text { prescribed drug }\end{array}$ & \multicolumn{1}{|c}{$\begin{array}{c}\text { Generic name or } \\
\text { drug group }\end{array}$} & $\begin{array}{c}\text { No(\%) of patients } \\
\text { prescribed drug }\end{array}$ \\
\hline Nitrazepam & $71(43)$ & Flurazepam & $5(3)$ \\
Temazepam & $34(21)$ & Barbiturates & $4(2)$ \\
Diazepam & $19(11)$ & Dichloralphenazone & $2(1)$ \\
Antidepressants & $15(9)$ & Chlormethiazole & $2(1)$ \\
Triazolam & $6(4)$ & Chlorazepate dipotassium & $2(1)$ \\
Lorazepam & $5(3)$ & Chlorpromazine & $1(1)$ \\
\hline \multicolumn{5}{l}{ Total } \\
\hline
\end{tabular}

Respondents were also asked when they had last taken a sleeping tablet. Of those reporting use at least "sometimes," $89 \%$ had taken a hypnotic the night before the interview, while a further $8 \%$ reported taking such drugs in the preceding week. The time since last taking a hypnotic was not significantly related to age or sex.

\section{DURATION OF USE}

Of those reporting the use of hypnotics at least "sometimes," $27 \%$ reported taking these drugs for less than one year. Durations of $1-5$ years, $5-10$ years, and more than 10 years were reported by the remaining $30 \%$, $19 \%$, and $25 \%$, respectively. The duration of hypnotic drug use was significantly related to age, with the younger age group (65-74) tending to predominate among the longer term users $\left(\chi^{2}=8.28, \mathrm{df}=3, \mathrm{p}<0.05\right)$. Duration of use showed no significant relation with sex.

\section{DRUGS PRESCRIBED}

Table III shows the distribution of hypnotic drugs prescribed. The most frequently prescribed drug was nitrazepam (accounting for $43 \%$ of all prescriptions). To some extent, the reported duration of drug use reflected the length of time a particular preparation had been on the market. Thus
$63 \%$ of those taking diazepam and $55 \%$ of those taking nitrazepam reported using drugs for longer than five years. A similar duration of use was reported by only $32 \%$ of those using temazepam.

\section{Discussion}

In 1980 the Committee on the Review of Medicines recommended that benzodiazepine hypnotics among the elderly should be prescribed "for short periods of time, and only after careful consideration." 10 Nevertheless, the fairly high levels of hypnotic drug use found in this survey are very similar to those reported throughout 1961-82." Thus from our data and those reported earlier it seems that roughly $10-15 \%$ of the elderly population take a hypnotic drug each night. In Britain this translates into between 0.8 million and 1 million people each night. In addition to fairly high levels of use, protracted use, often over five years, continues to typify consumption of hypnotic drugs among the elderly. Furthermore, judging by the high proportion of the users in our study who reported taking a hypnotic on the night before the interview regular long term use is not uncommon.

The likelihood of having a hypnotic drug prescribed seemed, as in other surveys, to increase with age, particularly among women. ${ }^{11}$ It is particularly interesting, however, to note that while sex seems to influence the overall level of use of hypnotic drugs significantly, it was not associated with the reported duration or likely frequency of use.

The most frequently prescribed drug was nitrazepam, a particularly long acting hypnotic associated with confusional states, impaired psychomotor performance, ${ }^{2}$ and residual sedation ${ }^{12}$ in elderly patients. Nevertheless, there was evidence in our study of a transition from longer to shorter acting hypnotic agents. Given the relation already described between duration of drug use and the actual drug prescribed, it should be noted that many of those using nitrazepam were probably the survivors of earlier prescribing practices. In contrast, among those who had been taking hypnotics for only a fairly short time a preference for shorter half life products was evident.

Estimates of the effective "lifespan" of hypnotic drugs vary, with the Committee on the Review of Medicines supporting the suggestion that "most hypnotics tend to lose their sleep promoting properties within three to 14 days of continuous use." 10 From our data, therefore, it seems that many, perhaps most, elderly users of hypnotic drugs are unnecessarily exposed to the risks of drug accumulation or daytime withdrawal effects. Furthermore, the overall pattern of use of hypnotic drugs in this representative sample was consistent with the development of benzodiazepine dependence in a substantial number of elderly patients.

This study was conducted by the Activity and Ageing Research Group, supported by a grant from the Grand Charity.

\section{References}

1 Evans JG, Jarvis EH. Nitrazepam and the elderly. Br Med $\mathcal{f}$ 1972;iv:487.

2 Morgan K. Effects of repeated dose nitrazepam and lormetazepam on psychomotor performance in the elderly. Psychopharmacology 1985;86:209-11.

3 Morgan K, Oswald I. Anxiety caused by a short life hypnotic. Br Med f 1982;284:942.

4 Oswald I, Adam K, Borrow S, Idzikowski C. The effects of two hypnotics on sleep, subjective feelings and skilled performance. In: Passouant P, Oswald I, eds. Pharmacology of the states of alertness. Oxford: Pergamon Press, 1979:51-63.

5 Higgit AC, Lader MH, Fonagy P. Clinical management of benzodiazepine dependence. $\mathrm{BrMed} \mathcal{f}$ 1985;291:688-90.

6 Adam K, Oswald I, Shapiro C. Effects of loprazolam and of triazolam on sleep and overnight urinary cortisol. Psychopharmacology 1984;82:389-94.

7 Ebrahim S, Morgan K, Dallosso H, Bassey J, Harries U, Terry A. Interviewing the elderly about their health: validity and effects on family doctor contacts. Age Ageing 1987;16:52-7.

8 Morgan K, Dallosso HM, Arie T, Byrne EJ, Jones R, Waite J. Mental health and psychological wellbeing among the old and the very old living at home. Br F Psychiatr 1987;150:801-7.

9 Office of Population Censuses and Surveys. Census 1981: sex, age, and marital status. London: HMSO, 1983.

10 Committee on the Review of Medicines. Systematic review of the benzodiazepines. Br Med $\mathcal{F}$ $1980 ; \mathrm{i}: 910-2$.

11 Morgan K. Sedative-hypnotic drug use and ageing. Arch Gerontol Geriatr 1983;2:181-99.

12 Greenblatt DJ, Allen M. Toxicity of nitrazepam in the elderly: a report from the Boston collaborative drug surveillance program. Br f Clin Pharmacol 1978;5:407-13.

(Accepted 3 November 1987) 